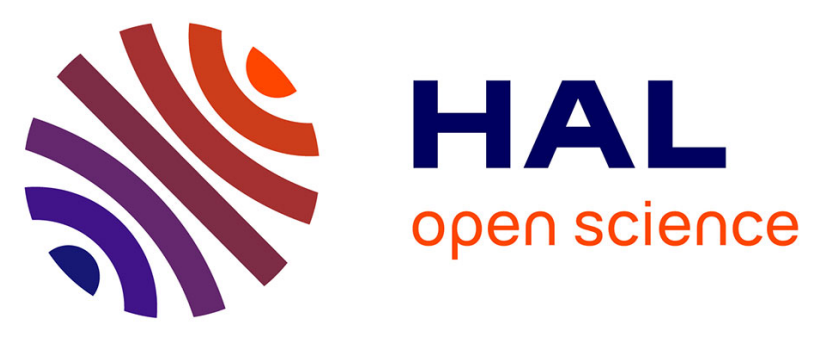

\title{
In search of stress odours across species: behavioural responses of rats to faeces from chickens and rats subjected to various types of stressful events
}

Vincent Bombail, Blandine Barret, Aurélien Raynaud, Nathalie Jerome, Audrey Saint Albin, Carsten Ridder, Anne Collin, Christine Leterrier, Laurence L.A. Guilloteau, Birte L. Nielsen

\section{To cite this version:}

Vincent Bombail, Blandine Barret, Aurélien Raynaud, Nathalie Jerome, Audrey Saint Albin, et al.. In search of stress odours across species: behavioural responses of rats to faeces from chickens and rats subjected to various types of stressful events. Applied Animal Behaviour Science, 2018, 205, pp.216-226. 10.1016/j.applanim.2017.10.013 . hal-02625299

\section{HAL Id: hal-02625299 \\ https://hal.inrae.fr/hal-02625299}

Submitted on 26 May 2020

HAL is a multi-disciplinary open access archive for the deposit and dissemination of scientific research documents, whether they are published or not. The documents may come from teaching and research institutions in France or abroad, or from public or private research centers.
L'archive ouverte pluridisciplinaire HAL, est destinée au dépôt et à la diffusion de documents scientifiques de niveau recherche, publiés ou non, émanant des établissements d'enseignement et de recherche français ou étrangers, des laboratoires publics ou privés.

$$
\text { Copyright }
$$




\section{Accepted Manuscript}

Title: In search of stress odours across species: behavioural responses of rats to faeces from chickens and rats subjected to various types of stressful events

Authors: Vincent Bombail, Blandine Barret, Aurélien Raynaud, Nathalie Jerôme, Audrey Saint-Albin, Carsten

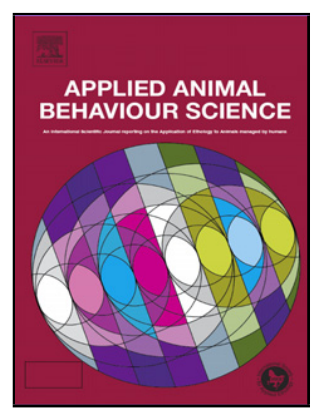

Ridder, Anne Collin, Christine Leterrier, Laurence A.

Guilloteau, Birte L. Nielsen

PII: $\quad$ S0168-1591(17)30298-8

DOI: $\quad$ https://doi.org/10.1016/j.applanim.2017.10.013

Reference: $\quad$ APPLAN 4540

To appear in: $\quad$ APPLAN

Received date: $\quad 20-5-2017$

Revised date: 6-10-2017

Accepted date: $\quad$ 16-10-2017

Please cite this article as: Bombail, Vincent, Barret, Blandine, Raynaud, Aurélien, Jerôme, Nathalie, Saint-Albin, Audrey, Ridder, Carsten, Collin, Anne, Leterrier, Christine, Guilloteau, Laurence A., Nielsen, Birte L., In search of stress odours across species: behavioural responses of rats to faeces from chickens and rats subjected to various types of stressful events.Applied Animal Behaviour Science https://doi.org/10.1016/j.applanim.2017.10.013

This is a PDF file of an unedited manuscript that has been accepted for publication. As a service to our customers we are providing this early version of the manuscript. The manuscript will undergo copyediting, typesetting, and review of the resulting proof before it is published in its final form. Please note that during the production process errors may be discovered which could affect the content, and all legal disclaimers that apply to the journal pertain. 
In search of stress odours across species: behavioural responses of rats to faeces from chickens and rats subjected to various types of stressful events

Vincent Bombail $^{\mathrm{a}}$, Blandine Barret ${ }^{\mathrm{a}}$, Aurélien Raynaud ${ }^{\mathrm{a}}$, Nathalie Jerôme ${ }^{\mathrm{a}}$, Audrey Saint-Albin ${ }^{\mathrm{a}}$,

Carsten Ridder ${ }^{\mathrm{b}}$, Anne Collin ${ }^{\mathrm{c}}$, Christine Leterrier ${ }^{\mathrm{d}}$, Laurence A. Guilloteau ${ }^{\mathrm{c}}$, and Birte L. Nielsen ${ }^{\mathrm{a},{ }^{*}}$

${ }^{a}$ NBO, INRA, Université Paris-Saclay, 78350 Jouy-en-Josas, France

${ }^{b}$ Ridder-Creative Chemometrics, 8543 Hornslet, Denmark

${ }^{c}$ URA, INRA, 37380 Nouzilly, France

${ }^{d}$ PRC, INRA, CNRS, Université François Rabelais, IFCE, Centre Val de Loire, 37380 Nouzilly,

France

*Corresponding author:

Birte L Nielsen,

NeuroBiologie de l'Olfaction (NBO),

INRA, Bât 230, Domaine de Vilvert

78350 Jouy-en-Josas,

France

Phone: +33 (0) 134652408

Email: birte.nielsen@inra.fr

Word count: 8795 (+53 references) 


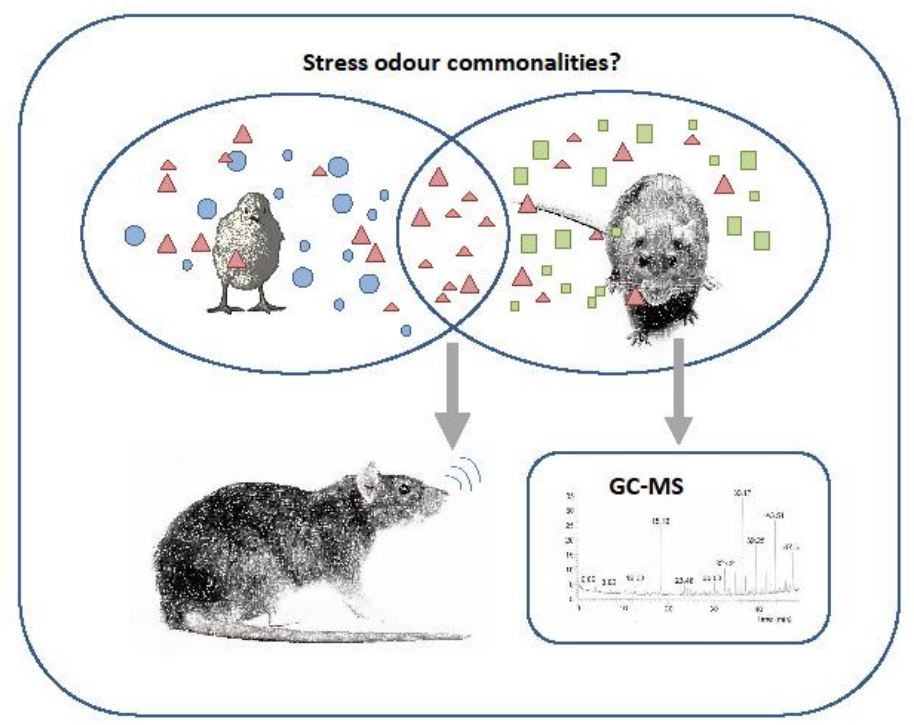

\title{
Highlights
}

- Rats responded differently to faeces from stressed or control chickens

- Similar response differences were seen with faeces from stressed or control rats

- Commonalities in odorous stress signatures across species are suggested

- At least ten molecules contributed to the odour in faeces from acutely stressed rats

\begin{abstract}
Stressed animals have an increased risk of health and welfare problems, thus methods for easy and early stress detection is important for appropriate animal management. Using the ability of rats to distinguish between faeces odours from stressed and non-stressed conspecifics, we investigated whether rats could detect stress status in another species (the chicken), which would suggest a commonality in odorous stress signatures across species. We carried out four experiments to
\end{abstract} investigate the existence of stress-specific odours. In the first experiment using a T-maze, male Brown Norway $(\mathrm{BN})$ rats $(\mathrm{n}=12)$ were found to sniff the faeces samples from stressed rats and chickens less relative to the samples from non-stressed individuals $(\mathrm{P}<0.05)$. In the second experiment, where odours were presented in an arena one at a time, male $\mathrm{BN}$ rats $(\mathrm{n}=16)$ sniffed faeces samples from 
stressed rats and chickens for longer than those from non-stressed controls $(\mathrm{P}<0.05)$. Within each test, the same responses to stress odours were seen independent of species of origin. This suggests that both in rats and chickens stress gives rise to specific volatile organic compounds (VOCs). In a third experiment, faeces from chickens, which had been stressed or non-stressed at hatching and subsequently exposed or not to acute stress at two weeks of age were tested on male BN rats $(n=18)$. These rats were also tested with faeces from non-stressed and acutely stressed rats as well as herb odour (1-hexanol) used as control. Number of freezing episodes was higher when rats were exposed to any of the samples originating from stressed individuals compared to that observed with herb odour ( $\mathrm{P}$ $<0.05)$. Also, defensive burying was more likely to occur when rats were exposed to faeces from chickens stressed at hatching $(\mathrm{P}<0.05)$. Finally, a fourth trial analysed faecal samples from nonstressed and acutely stressed rats using gas chromatography coupled with mass spectrometry (GCMS), and identified ten VOCs potentially involved in the distinctive smell detectable in faeces from acutely stressed rats. These findings confirm the existence of stress-specific odours in rats and indicate that, although not necessarily identical, a similar type of odour may be present in stressed poultry. In addition, this odour could be detected by rats in chicken faeces collected almost two weeks after the birds had been exposed to a stressful event. Our results suggest that patterns of VOCs may have the potential to be used as a tool for early, non-invasive screening of stress status in animals.

Keywords: avian; inter-species; mammals; olfaction; stress indicator; stress types

\section{Introduction}

In some species, exposure to a stressful situation may give rise to specific body odours. Rats and mice give off specific odorous alarm signals (Zalaquett and Thiessen, 1991; Brechbühl et al., 2013; Inagaki et al., 2014), and rats have been shown capable of distinguishing between stressed and non-stressed conspecifics based on their odours (Valenta and Rigby, 1968; Mackay-Sim and Laing, 1980). Stress odours may depend on the type of stress experienced, where acute stress can give rise to specific odours thought to signal danger to conspecifics, as seen in mice (Brechbühl et al., 2013), whereas chronic stress odours may arise from lasting changes in the hormonal or metabolic state of the animal. As most work in this area have been carried out in mammals, particularly in rodents, we aimed to 
address the question whether birds, here represented by the domestic chicken, also exhibit a change in odour when stressed.

We decided to use rats as biological sensors of potential odour changes in the faeces from chickens that either had or had not been exposed to stressful events in early life. Rats and not chickens were chosen as the subject of behavioural study, as it is well-established that rats have very sensitive olfactory perception, and can distinguish between odours, which differ only slightly (e.g. Clarin et al., 2010). Also, even though faeces contain hundreds of different volatile molecules, rats can discriminate between different physiological states (oestrus vs dioestrus), even in other species (fox and horse; Rampin et al., 2006). They may thus be able also to detect potential differences in smell between stressed and non-stressed individuals of species other than rats.

Although chickens were not used in the present study for the purpose of odour detection, the existence of stress odours in avian species would nevertheless be more likely if birds are able to detect such odour changes themselves. Birds have a more acute sense of olfaction than previously thought. Petrels and albatrosses, for example, have been found to use odours when foraging for krill at sea (Nevitt et al., 2004). Jungle-fowl have individual odours emanating from their uropygial gland secretions (Karlsson et al., 2010), and chickens use olfaction in their social interactions to a surprising extent (Krause et al., 2016). For example, week-old chicks appear to find cat odour aversive (Fluck et al., 1996), showing that they are able to detect and distinguish between odours. Also, exposure to certain odours whilst still in the egg influence the feeding behaviour of young chickens once hatched (Bertin et al., 2010). These findings indicate that potential changes in body odours in birds caused by stress could be perceived by their conspecifics.

Some, although sparse, evidence exists as to the existence of avian odours indicative of stress.

Changes in the odour of bird excreta (henceforth referred to as faeces) caused by infection have been found in ducks, as mice were able to distinguish faeces from mallards infected with avian virus from that of non-infected birds (Kimball et al., 2013). Tullo et al. (2017) found differences in the 
composition of air samples taken from boxes of broilers with or without coccidiosis. Krause et al. (2016) suggest that olfactory cues are more reliable in signalling health status than visual signals, which often becomes apparent with a certain delay. However, it may be that such odour changes are associated with the stress response induced by the burden of being sick rather than the disease itself. If stress-induced odours exist in birds, monitoring of these odours could potentially be used for the detection of stress in poultry production where easy, non-invasive methods to measure stress are lacking.

The experiments described here form part of a larger project investigating the long-term consequences of exposure to stressful events in early life on the health and behaviour of production animals, including chickens. The overall aim of the four experiments reported in this article was to investigate olfactory-based, non-invasive indicators of stress across two very different species. This was done by studying the behavioural response of rats to faeces from stressed and non-stressed chickens, and comparing this to their response to faeces from stressed and non-stressed conspecifics (Experiments 13). The faeces used to detect stress odours were collected from animals immediately or several days after the stressful experience. Faeces from acutely stressed rats have a particular odour, detectable by humans, that differs from that of non-stressed rat faeces. We therefore also carried out analyses of the volatile organic compounds (VOCs) of acutely stressed and non-stressed rat faeces using mass spectrometry combined with gas chromatography (GC-MS) to investigate if specific stress molecules could be identified (Experiment 4). Each experiment is presented separately below with a short introduction followed by methods and results. For ease of reading, the results are briefly discussed when presented, and a broader discussion of the combined results is given at the end. All procedures used in the experiments reported in this article were approved by the local ethics committee (Comite d'éthique appliqué à l'expérimentation animale; permissions no.11/013, 12/154 and 01730.02) and carried out in accordance with current European legislation (EU Directive 2010/63/EU) and ethical guidelines (Sherwin et al., 2003). 


\section{Experiment 1: Simultaneous exposure to odours from stressed and non-stressed chickens and} rats

In order to compare the behavioural responses of rats to faeces from two different species, rats were exposed in a T-maze to faeces from either stressed and non-stressed chickens or faeces from stressed and non-stressed rats. We hypothesised that the expected differences in response to stressed and nonstressed rat faeces would be similar to that seen with the chicken faeces. The behavioural response measured were those used as standard in T-maze trials, and were not meant to measure any stress potentially experienced by the rat as a consequence of the odour exposure.

\section{$\underline{\text { 2.1 Materials and Methods }}$}

\subsubsection{Animals and housing}

We obtained male, 7-week-old Brown Norway rats $(\mathrm{n}=12)$ from a commercial breeder (JanvierLabs.com, France) and housed them in groups of three in conventional, multi-rack, plastic cages covered by a metal grill, with free access to commercial rat pellets and tap water. Cage cleaning was carried out weekly. The rats were accustomed to and kept in an inverse light cycle (12 h dark per $24 \mathrm{~h}$ starting at 07:00 h), and all handling of the rats were carried out in red lighting during the dark period when the rats are naturally active. 


\subsubsection{Faeces samples}

The chicken faeces were collected from 12-day-old male and female broiler chickens, which had been exposed to one of two treatments post-hatch in a previous study (Koch et al., 2015). Briefly, to mimic suboptimal conditions of broiler chick transport from hatchery to farm, newly-hatched chicks $(n=48)$ were deprived of feed and water and put in a transportation box whilst undergoing irregular movement and variable room temperature for 24 hours following hatching (Stress group). When removed from the transportation box, the birds were checked for signs of injury or disease (none were found), and moved into the experimental rearing facility and placed in 6 pens (LxW: $1 \mathrm{~m} \times 1 \mathrm{~m})$ of 8 birds. Another group of newly-hatched chicks $(n=48)$ from the same cohort were placed directly in the experimental rearing facility, also in 6 pens of 8 birds each, immediately after being withdrawn from the hatcher (non-stressed Control group). Fresh chicken faeces without caeca content were collected at 12 days of age from 6 pens per group as follows: collecting devices consisting of a box (LxWxH: 55 $\mathrm{cm} \times 40 \mathrm{~cm} \times 5 \mathrm{~cm}$ ) covered with wire mesh were present on the cage-floor of each pen of all groups of chickens (from day 0). In the morning on day 12, aluminium trays were placed under each box, and faeces samples were collected for $2 \mathrm{~h}$ and stored at $-80{ }^{\circ} \mathrm{C}$ in separate containers for each pen. Prior to testing, the samples were removed from the freezer, and all samples from each treatment (Stress or Control) were mixed within treatment. The two mixtures were divided into 0.5-1.0 g samples placed onto cotton disks, each wrapped in tinfoil and stored at $-20{ }^{\circ} \mathrm{C}$ until $30 \mathrm{~min}$ before use, where the samples were left at room temperature to defrost.

The rat faeces were collected from 24 male Wistar rats taking part in another experiment (see Raynaud et al., 2015). At the time of faeces collection, half of these rats had from 8 weeks of age been subjected for 17 days to a chronic variable stress schedule consisting of daily exposure to mild, unpredictable stress of a social, physical or dietary nature, which is a validated method commonly used to induce chronic stress in rats (Willner, 2005). The other 12 rats were non-stressed controls. Fresh faecal pellets were collected from the cage floor and stored for individual rats in glass tubes at $-80^{\circ} \mathrm{C}$. Prior to testing, the tubes were removed from the freezer, and samples were prepared by placing into a glass tube 3-4 pellets (1-2 g/sample) from at least two different individuals from the 
same treatment. The samples were stored at $-20{ }^{\circ} \mathrm{C}$ until $30 \mathrm{~min}$ before use, where they were left at room temperature to defrost.

\subsubsection{Elevated Plus-Maze test}

When the rats were 14 weeks of age, we tested them individually in a standard Elevated Plus Maze (EPM; black, with two open arms with short ledges and two enclosed arms, each $55 \mathrm{~cm} \mathrm{x} 10 \mathrm{~cm}$ and elevated $1 \mathrm{~m}$ above the floor) to assess their general anxiety level (Pellow et al., 1985). This was done to ascertain if differences in the emotional reactivity of the rats affected their response to stressful odours. Each test lasted $5 \mathrm{~min}$, and was carried out during the usual dark period in a fully lit room with 100 lux on the open arms, and video recorded for subsequent analyses.

\subsubsection{Behavioural test of faeces odours (in T-maze)}

The rats were subsequently habituated over several days to be alone in a large T-maze arena, which consisted of a rectangular open space $(77 \mathrm{~cm}$ x $51 \mathrm{~cm}$ ) with two accessible arms (WxL: $19 \mathrm{~cm} \times 25$ $\mathrm{cm}$ ) extending from each side at one end of the rectangle, forming a broad T-shape. No litter was used, and a perforated metal tea-ball was placed in a pre-drilled hole at the end wall of each arm of the maze. Each rat was tested 6 times on separate days. The test lasted $5 \mathrm{~min}$, and the first and last tests were done with empty tea-balls in both arms. These tests served as a baseline response for potential side preferences and to ensure that the level of interest in the two arms did not diminish with repeated testing. In the four odour tests, each rat was tested twice with rat faeces and twice with chicken faeces, alternating between faeces from the two species in consecutive tests. In each test the two tea-balls contained one stressed and one non-stressed sample, respectively, and always from the same species. Treatment order and side containing stress sample were balanced, so that on each test day rat faeces were used in half of the tests with the stressed sample presented three times in each arm, and similarly for the chicken faeces. All tests were video-recorded (Sony 12.0 mega pixels HDR-XR-500 Handycam) for subsequent analyses. From the videos, the same trained observer scored the following behaviour of each rat in each 5-min test: Number of entries into each arm, time spent in each arm and time spent sniffing each tea-ball. 


\subsubsection{Statistical analyses}

Differences in behavioural responses to rat and chicken faeces were tested by fitting odour (rat, chicken, empty) as fixed effect and time spent in open arm of the EPM as a covariate in a General Linear Model (Minitab Inc., ver 17.1; www.minitab.com) using Tukey pairwise comparisons post-hoc. One-sample, two-tailed t-tests were used on means within each species for each rat to test if the visits to each arm differed significantly from random (i.e. from 50\%). Significant differences are presented as least squares means and standard errors, otherwise overall means are given with standard deviations.

\section{$\underline{2.2}$ Results}

The percentage of time spent in the open arms of the EPM varied greatly among rats (Figure 1a) indicating a diversity of emotional reactivity (Hogg, 1996; Walf and Frye, 2007), but no significant effect of this measure, fitted as a covariate in the analysis, was found on the behavioural responses of the rats to the odours tested in the T-maze.

Frequency of entry into the arms of the T-maze during the odour tests did not differ significantly between tests (overall mean \pm SD: $9.8 \pm 2.13$ ). The rats spent longer in the two arms of the T-maze combined when the two tea-balls contained faeces (mean \pm SE: rat: $116.7 \pm 4.75 \mathrm{~s}$; chicken: $100.5 \pm 4.75$ s) than when these were empty $\left(91.8 \pm 4.75 ; F_{2,36}=7.1 ; P=0.003\right)$. The rats spent longer sniffing the two tea-balls when these contained rat faeces $(36.1 \pm 2.41 \mathrm{~s})$ than when they contained chicken faeces $(24.4 \pm 2.41 \mathrm{~s})$ or were empty $\left(19.1 \pm 2.41 ; \mathrm{F}_{2,36}=13.0 ; \mathrm{P}<0.001\right)$.

Within each odour category (rat faeces, chicken faeces, or empty), the rats spent less time sniffing the stressed faeces than they sniffed the control faeces for both chicken $(\mathrm{T}=-2.53 ; \mathrm{P}=0.028)$ and rat faeces $(\mathrm{t}=-2.88 ; \mathrm{P}=0.015)$ whereas visits to the two arms of the $\mathrm{T}$-maze did not differ from random (i.e. $50 \%)$ when the tea-balls contained no odour source $(\mathrm{t}=0.64 ; \mathrm{P}=0.534$; Figure $1 \mathrm{~b})$. 
Although the significant differences found were subtle, the rats responded differently to the two types of odour within species, and this response-difference was consistent across species. This would indicate that the rats were able to distinguish between stressed and control faeces based on odours, suggesting that there are odorous changes to chicken faeces caused by stress.

\section{Experiment 2: Separate exposure to odours from stressed and non-stressed chickens and rats}

In the second experiment, we wanted to separate the effects of stressed and non-stressed faeces by exposing the rats to one odour source at a time. The T-maze was therefore replaced by a rectangular, high-walled test-arena. The method for pre-characterising individual rats was also changed from an Elevated Plus Maze to an Open Field test. This was done because the EPM response had not affected significantly the subsequent test behaviour of the rats in Experiment 1, and another method was therefore employed to help account for any variation between individuals (Katz et al., 1981). As in the previous experiment, we hypothesised that any differences in response to stressed and non-stressed rat faeces would be similar to that seen with the chicken faeces.

\section{$\underline{\text { 3.1 Materials and methods }}$}

\subsubsection{Animals and housing}

Male Brown Norway rats $(\mathrm{n}=16)$ were obtained at the same time and age as the cohort for Experiment 1. Apart from being housed in pairs, they were raised in the same manner as previously described.

Prior to this study, the rats had taken part in another experiment investigating oestrus odours (Nielsen et al., 2016).

\subsubsection{Open Field test}

When the rats were 6 months old, we tested them individually in an Open Field (OF; L $\times \mathrm{W} \times \mathrm{H}: 100$ $\mathrm{cm} \times 100 \mathrm{~cm} \times 30 \mathrm{~cm}$ ) under red lighting during the usual dark period. Each test lasted $5 \mathrm{~min}$ and was video-recorded for subsequent analyses. Following the odour tests described below, we repeated the OF test. In order to quantify thigmotaxis (tendency to remain close to the arena walls), the OF was 
divided into a grid consisting of 25 squares of equal size, with the central nine squares defined as inner zone and the rest as outer zone. The proportion of time spent in the outer zone was scored for each rat by the same observer, and the number of lines crossed in the grid was used as a measure of activity.

\subsubsection{Behavioural test of faeces odours (in test arena)}

During the following week, the rats were habituated over several days to being placed alone in a test arena (LxWxH: $66 \mathrm{~cm}$ x $41 \mathrm{~cm}$ x $41 \mathrm{~cm})$. The test arena was made of transparent Plexiglas ${ }^{\circledR}$, and had a removable, perforated, transparent lid. The floor was covered with clean saw dust. At one end we placed an empty, stainless steel container (diameter $9.5 \mathrm{~cm}$; height $3.7 \mathrm{~cm}$; Grundtal IKEA) with a magnetic base. It had a screw-top lid with a plastic inset, which had been perforated to allow odour to escape without the rat being able to access the odour source. The magnetic base of the container was stuck to a metal plate fixed at the end wall of the arena to prevent the rats from standing on and urinating into the container, and a clean container was used for each test. Each test lasted $10 \mathrm{~min}$, as a pilot trial showed this to be sufficient to assess the interest of the rats in the odour. All rats were tested 6 times, with tests 1 and 6 being with an empty container (no odour). In the four odour tests, each rat was tested once with each type of odour (stressed rat faeces, control rat faeces, stressed chicken faeces, and control chicken faeces) in a Latin square design, i.e. all odours represented equally across test order and with each odour presented an equal number of times after any other odour (Bradley, 1958). Rat and chicken faeces were obtained from the same animals and in the same way as described for Experiment 1. All tests were video-recorded from above the test arena. The behaviour of the rats was scored by a trained observer with no knowledge of the treatment applied or identity of the rat in each video. In the odour tests, latency, frequency and duration were recorded for sniffing the odour container and for freezing (defined as being immobile whilst alert). In addition, the number of movements between the two halves of the arena was noted together with any occurrence of defensive burying, where the rats push the litter with their head and front paws, a behaviour which may indicate an attempt to cover an aversive stimulus (De Boer and Koolhaas, 2003). 


\subsubsection{Statistical analyses}

Data from the OF tests were analysed in Minitab (ver. 17.1) using one-sample, two-tailed t-test and Pearson correlation. Data from the odour tests were analysed in two General Linear Models, first analysing sniffing behaviour by fitting test order as fixed effect and rat as a random effect. This was done to investigate if the behaviour of the rats changed as the testing progressed. Subsequently, all variables from the four tests for each of the 16 rats involving an odour source were analysed fitting source species (rat or chicken) and stress level (+/-) and their interaction as fixed effects together with test order, whilst fitting activity during the $\mathrm{OF}$ test as a covariate. The occurrence $(0,1)$ of defensive burying in each test was tested in relation to odour using the non-parametric Friedman test. Significant differences are presented as least squares means and standard errors, otherwise overall means are given with standard deviations

\subsection{Results}

The rats showed significant thigmotaxis behaviour, all spending more than $76 \%$ of the time in the outer zone of the OF, which is significantly higher than the $64 \%$ (16 out of 25 squares) expected (mean $\pm \mathrm{SD}=88.0 \pm 6.61 ; \mathrm{T}=14.52 ; \mathrm{P}<0.0001$ ). Time spent in the outer zone was independent of the activity level of the rats $(\mathrm{r}=-0.37 ; \mathrm{P}=0.164)$, which was used as a co-variate in the subsequent analysis (Figure 2a). Activity in the OF was found to be a relatively stable characteristic within each rat, as it correlated positively with the same measurement in the second OF test $(r=0.53 ; \mathrm{P}=0.033)$ carried out at the end of the experiment.

No effect of test order was found on latency to sniff the container $\left(\mathrm{F}_{5,75}=0.5 ; \mathrm{P}=0.808\right)$ with an overall mean latency $( \pm \mathrm{SD})$ of $2( \pm 2.4) \mathrm{s}$, and a maximum latency of $14 \mathrm{~s}$ across all tests. Test order did not affect frequency $\left(\mathrm{F}_{5,75}=1.9 ; \mathrm{P}=0.109\right)$ or duration of sniffing the container $\left(\mathrm{F}_{5,75}=1.5 ; \mathrm{P}=\right.$ 0.189), indicating that the interest in the container did not wane as testing progressed.

No significant interactions between source (rat or chicken) and stress type (+/-) of faeces were found for sniffing the container. The rats spent significantly longer sniffing the faeces from stressed than 
from non-stressed animals (mean $\pm \mathrm{SE}=14.8 \pm 0.80$ vs. $12.6 \pm 0.88 \mathrm{~s} ; \mathrm{F}_{1,58}=3.1 ; \mathrm{P}=0.044 ;$ Figure $2 \mathrm{~b}$ ), but the frequency of sniffing did not differ significantly (mean $\pm \mathrm{SE}=6.4 \pm 0.23$ sniffing episodes $/ 10$ $\min$ ) between any of the four odour types. Also, no effects of odour types were found for freezing frequency and duration (means $\pm \mathrm{SE}=8.1 \pm 5.27$ episodes/10 min and $39.9 \pm 2.32 \mathrm{~s}$ in total, respectively), defecation frequency (mean $\pm \mathrm{SE}=3.5 \pm 0.26$ pellets) or movements between arena halves (mean $\pm \mathrm{SE}=12.1 \pm 0.50$ shifts) of the rats. Defensive burying occurred in $40 \%$ of the tests and did not differ between odours $\left(\mathrm{X}^{2}=3.06 ; \mathrm{df}=5 ; \mathrm{P}=0.690\right)$.

The change in experimental protocol meant that the behavioural response differed from that observed in experiment 1; however, the rats responded differently to the two types of odour within species, and this response-difference was consistent across species, as also found in experiment 1.

\section{Experiment 3: Exposure to odours from acutely stressed rats and chickens}

The previous two experiments had used faeces from rats exposed to intermittent chronic stress and from chickens, which had been exposed to a stressor 12 days prior to faeces collection. Given the relatively small effects on the behavioural response of the rats seen in these experiments, we wanted to investigate if exposure to faeces from acutely stressed rats and chickens would give rise to a more profound difference in the behaviour of rats. No tests (EPM or OF) were carried out prior to testing the rats with the odours.

\section{$\underline{\text { 4.1 Materials and Methods }}$}

\subsubsection{Animals and housing}

A cohort of male Brown Norway rats $(n=18)$ were obtained at 7 weeks of age, and housed and managed as the rats used for Experiment 2. Prior to this study, the rats had taken part in another experiment investigating odours from germ-free rats (data not yet published). At 5 months of age they were habituated to the same arena as used for odour tests in Experiment 2. 


\subsubsection{Faeces and odour samples}

We harvested fresh faecal pellets from un-stressed male Wistar rats (control: Ratc; $n=8$ ), and subsequently subjected them to a 20-min physical restraint test in a tube (acute stress: Rats). Fresh faecal pellets were collected from the cage floor during the $30 \mathrm{~min}$ following release from the restraint tube. This period was chosen to ensure that a sufficient quantity of fresh pellets was collected. All collected pellets were stored within treatment for individual rats in glass tubes at $-80{ }^{\circ} \mathrm{C}$. Prior to testing, the tubes were removed from the freezer, and samples were made from 2-3 pellets (mean $\pm \mathrm{SE}$ $=0.7 \pm 0.03) \mathrm{g} / \mathrm{sample}$ ) from at least two different individuals from the same treatment. These were placed onto cotton disks, each wrapped in tinfoil, and stored at $-20{ }^{\circ} \mathrm{C}$ until $30 \mathrm{~min}$ before use, where they were left at room temperature to defrost.

Faeces from chickens were collected from birds, which had been exposed (S) or not (C) to the same stress paradigm in the 24 hours following hatching as used in Experiments 1 and 2. When the chickens were 13 days old, fresh faeces were collected in the morning using the same method as described for Experiment 1 from 6 groups of 8 birds from treatment $S(n=48)$, and 6 groups from treatment $C(n=$ 48). Subsequently, half of the birds from each group were exposed to acute stress in the form of social isolation and thermal stress by each being placed alone in an opaque bucket without access to food and water in an ambient temperature of $18{ }^{\circ} \mathrm{C}$ for 2 hours (S). The other half remained in groups of 4 birds in their home environment at $25{ }^{\circ} \mathrm{C}$ with access to food and water (C). Collection of fresh faeces without caeca content gave rise to four types of faeces, all collected when the chickens were 13 days of age and stored at $-80{ }^{\circ} \mathrm{C}$ : CC and SC (collected in the morning), and CS and SS (collected from the buckets), where the first letter refers to the stress treatment at hatching, and the second letter to the stress treatment at day 13 of age. Prior to testing, the samples were removed from the freezer, mixed within treatment and divided into 0.5-1.0 g samples onto cotton disks, each wrapped in tinfoil and stored at $-20{ }^{\circ} \mathrm{C}$ until $30 \mathrm{~min}$ before use, where the samples were left at room temperature to defrost. 
A molecule with an herbaceous smell (1-hexanol diluted in 1,2-propanediol to $5000 \mathrm{ppm}$ ) was used a neutral control odour, as it had previously been found to be neither attractive nor aversive to male rats (Nielsen et al., 2013, 2016).

\subsubsection{Behavioural test of faeces and neutral odours}

The test was carried out in the same manner as used in experiment 2, except the container with the odour source was positioned on a metal plate on the floor at one end of the test arena (LxWxH: $66 \mathrm{~cm}$ x $41 \mathrm{~cm} \mathrm{x} 41 \mathrm{~cm}$ ). This was to allow more interaction with the odour source, including defensive burying, and by using clean containers for each test, the risk of urine- and cross-contamination was minimised. All rats were exposed to all odours, one at a time on different days, for $10 \mathrm{~min}$. The first test was herb odour for all rats and subsequently the 6 types of faeces (i.e. faeces from acutely stressed (Rats) and non-stressed control rats (Rat $)$, and the four types of chicken faeces: CC, CS, SC, and SS) were presented to the rats in a Latin square design. Latency, frequency and duration of freezing as well as any contact with the odour container were recorded by direct observation. In addition, any occurrence of defensive burying was noted as well as the number of movements between the two halves of the arena used as a proxy for activity.

\subsubsection{Statistical analyses}

Data from the odour tests were analysed in Minitab (ver. 17.1) in two General Linear Models, first without the herb control and fitting test order as fixed effect and rat as a random effect. This was done to investigate if the behaviour of the rats changed as the testing progressed. Subsequently, data from tests of all seven odours were analysed fitting odour as fixed effect and rat as a random effect to account for repeated measures. Herb was used as the control in all pair-wise comparisons. Data on latencies were square root transformed prior to analysis to ensure homogeneity of variance. The occurrence $(0,1)$ of defensive burying in each test was tested in relation to odour using the nonparametric Friedman test. Kruskal-Wallis tests were carried out on the weight of the rat faecal samples. Significant differences are presented as least squares means and standard errors, otherwise overall means are given with standard deviations. Latencies are presented as medians and quartiles. 


\subsection{Results}

A significant effect of test number was found for frequency of contact with the odour container $\left(\mathrm{F}_{5,80}=\right.$ 5.8; $\mathrm{P}<0.001)$ and frequency of freezing $\left(\mathrm{F}_{5,80}=3.7 ; \mathrm{P}=0.005\right)$, in both cases with the highest frequency observed in the second test, which for all rats were the test following the neutral herb odour. This higher freezing frequency was accompanied by a shorter duration of freezing bouts $\left(\mathrm{F}_{5,80}=2.9 ; \mathrm{P}=\right.$ 0.018), leading to no significant effect of test number on total duration of freezing $\left(\mathrm{F}_{5,80}=1.1 ; \mathrm{P}=\right.$ 0.380). The Latin square design ensured that all 6 types of faeces were represented equally, i.e. three rats tested with each for each test number, thus the effects found for test order would not affect the subsequent analyses.

All rats interacted with the container in all tests. No effect of odour was found on any of the variables relating to the container, i.e. latency $\left(\mathrm{F}_{6,102}=1.9 ; \mathrm{P}=0.084\right.$; median $\left.[\mathrm{Q} 1, \mathrm{Q} 3]=5.5[4,12] \mathrm{s}\right)$, frequency $\left(\mathrm{F}_{6,102}=0.7 ; \mathrm{P}=0.644 ;\right.$ overall mean $\pm \mathrm{SD}=13.9 \pm 4.92$ times/test $)$ and duration of contact with the container $\left(\mathrm{F}_{6,102}=1.5 ; \mathrm{P}=0.186\right.$; overall mean $\left.\pm \mathrm{SD}=146 \pm 62.5 \mathrm{~s}\right)$. Activity was also not affected by odour $\left(\mathrm{F}_{6,102}=1.1 ; \mathrm{P}=0.376\right.$; overall mean $\pm \mathrm{SD}=12 \pm 4.9$ changes between arena halves $)$.

All rats displayed episodes of freezing behaviour in all tests, and no effect of odour was found in the latency to freeze $\left(\mathrm{F}_{6,102}=1.8 ; \mathrm{P}=0.103 ;\right.$ median $\left.[\mathrm{Q} 1, \mathrm{Q} 3]=106[73,168] \mathrm{s}\right)$. The total duration of freezing was found to be significantly affected by odour $\left(\mathrm{F}_{6,102}=3.9 ; \mathrm{P}=0.002\right)$ with all odours except Rat $_{C}$ leading to longer total duration of freezing than observed with herb (Figure 3a). For number of freezing episodes $\left(\mathrm{F}_{6,102}=3.9 ; \mathrm{P}=0.002\right)$, only the non-stress samples (Rat $\mathrm{C}_{\mathrm{C}}$ and $\mathrm{CC}$ ) did not differ from the herb control (Figure 3b). Odour was also found to affect the proportion of rats displaying defensive burying $\left(X^{2}=20.4 ; d f=6 ; P=0.002\right)$, with the lowest number of rats observed pushing the litter when exposed to herb, and the highest number of rats pushing the litter observed for odours SC and SS (Figure 4), indicating that the stress treatment at hatching gave rise to the observed differences in defensive burying. This test was also significant when including only the four types of chicken faeces $\left(\mathrm{X}^{2}=11.8\right.$; $\mathrm{df}=3 ; \mathrm{P}=0.008)$. 
In contrast to experiments 1 and 2, the rats responded to the faeces from stressed animals with behaviour types indicative of anxiety and aversiveness in the form of more frequent freezing and defensive burying. However, the latter was not associated with odours of acute stress, and the significant differences found were subtle, despite the clear dissimilarities in odours emanating from the two types of rat faeces. When we analysed the weights of individual faeces samples from the nonstressed and acutely stressed rats, it became evident that despite using roughly the same number of faecal pellets in each sample, the weight of the samples (Kruskal-Wallis test; $\mathrm{H}=22.98$; $\mathrm{df}=1$; medians $=0.54$ vs $0.80 \mathrm{~g}$ for Rat $\mathrm{C}$ vs Rats, respectively; $\mathrm{P}<0.0001)$ as well as the weight of the pellets differed significantly $\left(\mathrm{H}=23.13 ; \mathrm{df}=1\right.$; medians $=0.18$ vs $0.28 \mathrm{~g} /$ pellet for Rat $\mathrm{C}_{\mathrm{C}}$ vs Rats, respectively; $\mathrm{P}<0.0001)$. These findings inspired us to perform the subsequent experiment.

\section{Experiment 4: GC-MS analyses of faeces from acutely stressed and control rats}

Whilst collecting the rat faeces used in Experiment 3, we noticed that the faecal pellets from the acutely stressed rats had a distinct odour detectable by the human handler. These pellets also appeared to contain more moisture and were found to weigh more than pellets collected from the non-stressed rats. Although

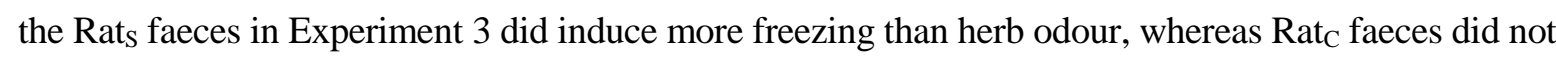
(Figure 3), the difference in behavioural response to these two odours was negligible. This was somewhat surprising, given the detectable odour difference, and we decided to make an attempt to identify the molecules giving rise to the distinct odour in the faeces from acutely stressed rats.

\section{$\underline{\text { 5.1 Materials and Methods }}$}

\subsubsection{Faeces samples}

Using the same procedure as in Experiment 3, we harvested faeces from individual male Wistar rats (n $=16$ ) before subjecting half of the rats to a 20 -min physical restraint test in a tube, whereas the other half were left un-restrained as un-stressed controls. Fresh faecal pellets were collected from the cage floor during the $30 \mathrm{~min}$ following release from the restraint tube (acutely stressed rats, $\mathrm{S}_{\text {post }}$ ) or no 
handling (non-stressed controls, $\mathrm{C}_{\text {post) }}$. These pellets, as well as the ones collected from the same rats before treatment $\left(\mathrm{S}_{\text {pre }}\right.$ and $\left.\mathrm{C}_{\text {pre }}\right)$ were counted, weighed and stored at $-80{ }^{\circ} \mathrm{C}$ for individual rats directly into $20 \mathrm{ml}$ glass vials sealed by metal screw-caps with pre-notched Teflon-silicone septa. This was done to prevent subsequent handling and exposure of the pellets before gas chromatography (GC) analysis. Two rats produced no faeces, one $\mathrm{C}_{\text {pre }}$ and one $\mathrm{C}_{\text {post. }}$

\subsubsection{GC-MS analysis}

Volatile components were extracted by Head Space-Solid Phase MicroExtraction (HS-SPME), using a

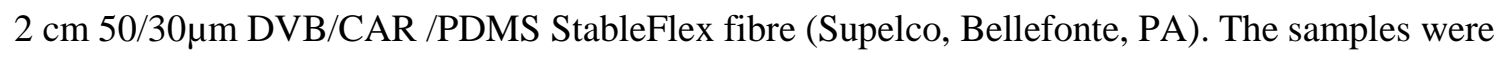
incubated and shaken for $40 \mathrm{~min}$ (using a $10 \mathrm{~s}$ on/off cycle) at $60{ }^{\circ} \mathrm{C}$, with the fibre introduced halfway through this period (TriPlus RSH with SPME module; Thermo Scientific, USA). Subsequently the fibre was inserted into the injector port of the GC (Thermo Scientific ${ }^{\mathrm{TM}}$ Trace $^{\mathrm{TM}}$ 1300, Thermo Fisher Scientific Inc., USA) for $1 \mathrm{~min}$ at $250{ }^{\circ} \mathrm{C}$ with a split ratio of 8.3 . The volatile compounds were separated using a DB-FFAP column $(60 \mathrm{~m} \times 0.32 \mathrm{~mm}$ internal diameter $\times 1 \mu \mathrm{m}$ film thickness $)$. Helium was used as the carrier gas at a constant flow rate of $1.2 \mathrm{ml} / \mathrm{min}$. The oven temperature profile was started at $40{ }^{\circ} \mathrm{C}$ for $5 \mathrm{~min}$, and then was programmed to reach $240{ }^{\circ} \mathrm{C}$ at a rate of $3{ }^{\circ} \mathrm{C} / \mathrm{min}$, staying at $240{ }^{\circ} \mathrm{C}$ for $15 \mathrm{~min}$. The GC-MS transfer line temperature was set at $250{ }^{\circ} \mathrm{C}$. The mass spectrometer (TSQ 8000, Thermo Fisher Scientific Inc.,, USA) operated in the scan mode at 70eV with the electron ionization source kept at $260{ }^{\circ} \mathrm{C}$.

\subsubsection{Data handling and analysis}

A total of 134 different peaks were identified and the relative abundance (area under the curve; AUC) was calculated for all peaks found in each sample. One peak was found in only one sample, and was excluded from further analysis. Prior to identification, the AUC values for the remaining 133 peaks were statistically analysed using the Latentix software (LatentiX Aps., Frederiksberg, Denmark; www.latentix.com) in a Partial Least Squares Discriminant Analysis (PLS-DA) for the following reason: The various compounds identified by the GC-MS analyses are quantified only as relative abundance within each sample. We therefore cannot compare the quantities directly, neither within nor 
between samples. The PLS-DA merges the different variables (peaks) into new variables (Principal Components), which describes the data across the totality of the characteristics. PLS-DA is different from standard principal component analysis as the eigen-vectors are rotated to catch more of the variation in the known treatments as opposed to that of the variables (peaks). The PLS-DA is an explorative analysis, putting emphasis on where in the resulting space the different sample types are found, i.e. which variables separate them. For the PLS-DA, the AUC values within each sample were standard normal variate (SNV) transformed to a mean of 0 and a standard deviation of 1 . For each peak these data were mean centred by subtracting the mean across samples from the individual sample values. Projecting these data onto the resulting Principal Components (PCs) gives a score for each rat. The variance described by each PC was calculated as the square-root of the sum of squares for the scores. Although scores and loadings have different units, they are geometrically related; so in order to display a bi-plot of the loadings for each of the peaks together with the scores for each rat, these data were scaled by the Eigen-value for each PC.

\section{$\underline{5.2 \text { Results }}$}

The PLS-DA model used described $44 \%$ of the variation in the GC-MS peaks and $53 \%$ of the variation in the treatment ( $S_{\text {post }}$ vs the rest). The bi-plot of loadings for each of the 133 peaks and the scores for each sample for the first two Principal Components is shown in Figure 5a. The samples from the acutely stressed rats $\left(S_{\text {post }}\right)$ cluster in the first quadrant and are separated from the remaining samples, indicated by a solid circle in Figure 5a, with the exception of one sample. It is also clear from the figure that ten of the peaks exert a greater influence than the rest on the separation of stressed from non-stressed samples, i.e. the ten data points outside the stippled oval in Figure 5a. The identity of these ten compounds are given in Table 1. However, when the PLS-DA was repeated with only these ten peaks included, the separation of the stressed ( $\left.\mathrm{S}_{\text {post }}\right)$ from the non-stressed samples $\left(\mathrm{C}_{\mathrm{pre}}, \mathrm{S}_{\mathrm{pre}}\right.$, and $\left.\mathrm{C}_{\text {post }}\right)$ was much less profound (Figure 5b) indicating that other peaks (and thus other compounds) also play a role.

Similar to our observations in Experiment 3, sample type affected the weight of the faecal pellets $\left(\mathrm{F}_{1,26}=\right.$ 5.9; $\mathrm{P}=0.022$ ) with pellets in the $\mathrm{S}_{\text {post }}$ samples being heavier than $\mathrm{S}_{\text {pre }}$, the latter collected from the same 
rats prior to the stress treatment $(\mathrm{T}=2.92 ; \mathrm{P}=0.034$; Figure $6 \mathrm{a})$. When linking faecal pellet weight before and after stress treatment for individual rats (Figure 6b) the increase in weight for all acutely stressed rats is clearly visible. Only one rat in the control group (open diamond in $\mathrm{C}_{\text {post }}$ in Figure $6 \mathrm{~b}$ ) also greatly increased the pellet weight after treatment although this group was not supposed to be stressed. Interestingly, this sample with the much heavier $\mathrm{C}_{\text {post }}$ pellets is also the only sample not separating from the cluster of stressed samples in the PLS-DA results (Figure 5a). This is not a consequence of pellet weight per se as other $\mathrm{C}_{\text {post }}$ samples contain pellets heavier than those found in $\mathrm{S}_{\text {post }}$ (Figure 6b).

\section{General discussion}

The behaviour of the rats, i.e. their spontaneous response during tests, was affected by odours from stressed animals, whether originating from rats or chickens. The first two experiments used different testing paradigms and as a result yielded different types of responses to stressed faeces, but within each test, the same responses to stressed faeces were seen independent of species of origin. This would indicate that - like in rats - stress also gives rise to stress-specific odours in chickens, and that these odours are detectable by rats. In the third experiment, number of freezing episodes was higher when rats were exposed to any of the samples originating from stressed individuals compared to that observed with herb odour. Also, defensive burying was more likely to occur when exposed to faeces from chickens stressed at hatching. Finally, GC-MS analyses of faecal samples from non-stressed and acutely stressed rats identified ten compounds potentially involved in the distinctive smell detectable in faeces from acutely stressed rats.

At least three issues arise from this series of experiments: The first relates to the different types and timing of stress treatments used in these experiments. The second issue concerns the ten potential molecules identified in the PLS-DA. And finally, what is the evidence and evolutionary context of similarities in odorant markers across animal species? These will be discussed in turn in the following. 


\subsection{Types and timing of stress treatments}

Different stress treatments were employed in connection with the harvesting of the faeces tested in the experiments presented here. An intermittent chronic stress paradigm was used to obtain the stressed rat faeces in Experiments 1 and 2, whereas faeces were collected from acutely stressed rats in

Experiments 3 and 4. Rats exposed to repeated stress have higher basal levels of corticosterone, but no longer show an increase in this stress hormone when subjected to the stressor (Pitman et al., 1988).

Our finding that the acutely stressed rats produced heavier, moister, and more odorous faecal pellets than the control group shows that acute stress leads to a sudden deposit of liquid organic matter into the faeces. Indeed, Castagliuolo et al. (1996) found an increased release of mucin (glycosylated proteins) from the colon of acutely stressed rats. Sakuma et al. (2013) tested faecal samples from female mice stressed in various ways, and human panellists described these faecal pellets as having an intense unpleasant odour. Surprisingly, Mackay-Sim and Laing (1981) wrote that faeces might not be the source of stress-specific odours in rats. Our results suggest otherwise, not least based on the separation of faeces samples from control and acutely stressed rats based on differences in their spectre of volatile compounds (Experiment 4). Jones and Roper (1997), in their review on olfaction in the domestic fowl, state that the faeces of frightened chickens differ in consistency and smell from that of unstressed birds. Mason (1975) found that young chicks displayed tonic immobility more readily and for longer when exposed to the odour of conspecifics receiving electric shocks repeatedly (cited from Jones and Roper, 1997). This demonstrates that acute stress in poultry leads to a change in the odorant characteristics of their faeces as has also been found in rats.

The male rats reacted to the chronic stressed rat faeces in a similar manner as to faeces from 12-dayold chickens, which had been stressed for 24h after hatching (Experiments 1 and 2). The choice of stressor used for the birds reflected the type of movement, temperature fluctuations, and food and water deprivation that newly-hatched commercial chicks are likely to experience during transport from the hatchery to the production unit. The stress treatment gave rise to a reduced growth of these birds relative to control chicks, which persisted until slaughter at 33 days of age (Koch et al., 2015). The stress treatment at hatching also gave rise to more defensive burying when the rats were exposed to 
faeces samples collected from these chickens on day 12 post-hatch (Experiment 3 ). This behaviour is an active negative response to a stimulus compared to freezing, which is a passive negative response, both of which indicate aversion to the stimulus in question (De Boer and Koolhaas, 2003). In combination, our results point towards different odorant characteristics in the faeces from stressed versus non-stressed birds, even when the stressors were no longer applied. One possible explanation is that the stressed birds were kept in a separate room during the stress-treatment post-hatch, which could have led to a different microbiota in these birds compared to the control group that was placed in the rearing pens immediately after hatch. The VOCs in faeces are also likely to be influenced by long-term changes in metabolism or physiology in early-stressed birds. This, in combination with the microbiota, may have given rise to persistent (and by rats detectable) differences in odour almost two weeks after stress exposure of the chicks.

\subsection{Candidate volatile molecules involved in stress-specific odours}

In Experiment 4, we identified ten compounds which contributed the most to the discrimination between stressed and non-stressed rat faeces in the PLS-DA. They comprised a wide group of compounds from different chemical families. Five of these were found in the same quadrant as the acute stress samples in the plot from the PLS-DA: an alkene (2-octene); butyric acid, two phenols (or one alcohol), and indole. Of these, the peak found to be phenol-n-methyl or phenylmethanol is the most exciting result: preliminary GC-MS analyses of chicken faeces points towards this peak and associated compound as being more abundant in faeces from stressed birds (L. Guilloteau, unpublished data). Confirmation of this finding would contribute greatly to explaining the behavioural results of Experiments 1 and 2, but further chemical analysis is warranted.

The remaining compounds identified have less obvious roles in provoking the observed behavioural response of the rats. Butyric acid contributes to the smell of human vomit, and was one of five compounds found to be lower in faeces from female rats in oestrus (Nielsen et al., 2011). A derivative of indole, the amino acid tryptophan, is the precursor of the neurotransmitter serotonin, and intestinal indole 3-acetic acid has been implicated in development and functioning of the stress axis (O'Mahony 
et al., 2015). Also, the mice detecting avian influenza in ducks, as mentioned in the introduction, may have reacted to an increase in acetoin (3-hydroxy-2-butanone) found in the faeces from the infected ducks (Kimball et al., 2013).

Some studies have analysed other sources of odour, such as urine and gland secretion. Schaefer et al. (2010) identified 15 compounds in mouse urine associated with stress, including one carboxylic acid (isovaleric acid) and several ketones and alcohols, but including none of the ten compounds we found in the rat faeces. In their study, 4-methyl phenol was found to be associated with aging, and they did find sulfur-containing compounds in nearly all their urine samples, including DMTS. None of the 17 volatile molecules identified by Sakuma et al. (2013) in the faeces of stressed female mice overlapped with our findings, although isobutyric acid and dimethyl disulphide were among the compounds they listed. Inagaki et al. (2014) identified a mixture of two aldehydes (4-methylpentanal and hexanal) as being the odorant carriers of the alarm signal found in the anal gland of rats. Gawienowski and Stacewicz-Sapuntzakis (1978) demonstrated an attraction of rats to sulfur compounds, although DMTS was not among the odours tested. It should be noted that compounds found in different body excretions may not be associated with each other, hence the discrepancy in the findings cited.

\subsection{Evolutionary context of similarities in odorant markers across animal species}

Changes in the odorant profile of individuals that are ill, stressed, or frightened are well-documented across a number of species and scenarios. Different animal species have been found capable of detecting diseases via odour changes such as cancer (dogs: McCulloch et al., 2006; fruit flies: Strauch et al., 2014) and tuberculosis (pouched rats: Weetjens et al., 2009) in humans (Bijland et al., 2013), and nematode infections in sheep (dogs: Richards et al., 2003). Changes in breath composition of dairy cows can be indicative of ketosis (Dobbelaar et al., 1996); and similar changes have been found in the breath of diabetic humans (Yu et al., 2005). Diseases usually develop over time and are associated with various physiological changes likely to give rise to these specific odours. Changes in the smell of an individual may also require that the signature odour of the animal in question (Wyatt, 2010) is known beforehand by group members, in order for them to detect a change. This is well- 
established in rodents, but various other species are able to distinguish between the odours of urine from different conspecifics (e.g. pigs: Meese et al., 1975; red squirrels: Vaché et al., 2001). In addition, detection of diseased states in other species via odour may have the evolutionary advantage of preventing the consumption of sick prey.

At the opposite end of this scale are alarm-signals that need to be instantaneous and easily detectable in order to be effective. Vocal alarms fall into this category, but may also alert a predator to the presence of a prey. A sudden emission of specific and highly volatile odorant compounds would serve as a detectable warning to near-by conspecifics also in the vicinity of the potential danger. Such odorant alarm-signals have been identified in rodents (Brechbühl et al., 2013; Inagaki et al., 2014), and there is some evidence of the presence of alarm substances in cow urine (Boissy et al., 1998). The finding that a rat will respond to its own alarm odour indicates that the smell carries a general message of danger (Inagaki et al., 2012). Even if the odour now functions as a signal of danger to conspecifics, this is likely to be a consequence of detectable odour differences which has been selected for and strengthened over the course of evolution, both in the emitter and the receiver. As described earlier, they may arise from sudden changes in metabolic or microbiotic activity, or originate from specific glands. In some species the information carried by an alarm odour appears to be innate (e.g. cichlids: Nelson et al., 2013), but many semiochemical effects arise from the animal learning to associate a given odour with the likelihood of an event, and this response may improve with training (Nielsen $e t$ al., 2015). Such learning is likely involved in the identification of odorant changes in conspecifics caused by stress, especially when the stress is of a certain duration. It should also be noted that we did not find any effect of individual differences in anxiety (as assessed by EPM and OF tests) on the response of the rats to the stress odours presented.

Why would stress odours share characteristics across species? Wyatt (2010) proposed that the use of the same compounds by different species reflects chemical constraints relating to stability, volatility, or toxicity of the compounds. Mice have been found to incorporate compounds of predator odour in their alarm signals (Brechbühl et al., 2013), thereby increasing the danger signal. Given that many 
vertebrates share the basic physiological pathways of stress responses, it is not improbable that stress gives rise to certain common chemical changes, which in turn will be part of any stress-specific modification of bodily odour. Our findings, suggesting that rats and chickens may share similar odorant markers of stress, is supporting this argument.

\section{Conclusion and perspectives}

The combination of behavioural responses and chemical analyses carried out in this series of experiments confirms the existence of stress-specific odours in rats and indicates that, although not necessarily identical, a similar type of odour may be present in stressed chickens. The odour from stressed chickens generated a similar response in rats as those seen with odours from stressed rats. Stressed animals are likely to have an increased risk of health and welfare problems, thus easy and early stress detection will contribute greatly to our ability to manage animals better in terms of their health and welfare. If patterns of VOCs are found to be specific to a state of stress in young animals, this may be used as a tool for early, non-invasive screening of stress levels.

\section{Acknowledgements}

The authors are grateful for the mathematical and computational inputs from S. Labarthe and $\mathrm{N}$.

Meunier, for the GC-MS analyses carried out by I. Pellerin, (UPMC), and to S. Crochet, E. CailleauAudouin and A. Koch (URA, INRA), I. Grimaud-Jottreau, E. Ledru, P. Ganier, F. Mercerand, J. Delaveau, C. Rat, and D. Gourichon (UE PEAT, INRA) and P. Constantin and G. Mauboussin (UMR PRC, INRA) for their skilled technical assistance. This study was supported by a grant from the Integrated Management of Animal Health metaprogram of INRA for the 'GISA - WHELP' project (www.gisa.inra.fr/en) and by a Credits Incitatifs grant from the Department of Animal Physiology and Livestock Systems (PHASE), INRA, France. 


\section{References}

Bertin, A., Calandreau, L., Arnould, C., Nowak, R., Lévy, F., Noirot, V., Bouvarel, I., Leterrier, C., 2010. In ovo olfactory experience influences post-hatch feeding behaviour in young chickens. Ethol. 116, 1027-1037. DOI: 10.1111/j.1439-0310.2010. 01820.x

Bijland, E.K., Bomers, M.K., Smulders, Y.M., 2013. Smelling the diagnosis: a review on the use of scent in diagnosing disease. Neth. J. Med. 71, 300-307.

Boissy, A., Terlouw, E.C.M., Le Neindre, P., 1998. Presence of cues from stressed conspecifics increases reactivity to aversive events in cattle: evidence for the existence of alarm substance in urine. Physiol. Behav. 63, 489-495.

Bradley, J.V., 1958. Complete counterbalancing of immediate sequential effects in a Latin square design. J. Amer. Statist. Ass. 53, 525-528.

Brechbühl, J., Moine, J., Klaey, M., Nenniger-Tosato, M., Hurni, N., Sporkert, F., Giroud C., Broillet M.C., 2013. Mouse alarm pheromone shares structural similarity with predator scents. P. Natl. Acad. Sci. USA 110, 4762-4767. DOI: 10.1073/pnas.1214249110

Castagliuolo, I., LaMont, J.T., Qiu, B., Fleming, S.M., Bhaskar, K.R., Nikulasson, S.T., Kornetsky, C., Pothoulakis, C., 1996. Acute stress causes mucin release from rat colon: role of corticotropin releasing factor and mast cells. Am. J. Physiol. 271, G884-G892.

Clarin, T., Swetlana, S., Apfelbach, R.,2010. Odor detection and odor discrimination in subadult and adult rats for two enantiomeric odorants supported by c-fos data. Behav. Brain Res. 206, 229-235. DOI: $10.1016 /$ j.bbr.2009.09.022

De Boer, S.F., Koolhaas, J.M., 2003. Defensive burying in rodents: ethology, neurobiology and psychopharmacology. Eur. J. Pharmacol. 463, 145-161. DOI: 10.1016/S0014-2999(03)01278-0

Dobbelaar, P., Mottram, T., Nyabadza, C., Hobbs, P., Elliott- Martin, R.J., Schukken, Y.H., 1996. Detection of ketosis in dairy cows by analysis of exhaled breath. Vet. Quart. 18, 151-152. DOI: $10.1080 / 01652176.1996 .9694638$

EU Directive 2010/63/EU of the European Parliament and of the Council of 22 September 2010 on the protection of animals used for scientific purposes. Off. J. Eur. Union, L276, 33-79 [20.10].

Fluck, E., Hogg, S., Mabbutt, P.S., File, S.E., 1996. Behavioural and neurochemical responses of male and female chicks to cat odour. Pharmacol. Biochem. Behav. 54, 85-91.

Foury, A., Helbling, J.C., Collin, A., Crochet, S., Lagarrigue, S., Désert, C., Mercerand, F., Delaveau, J., Koch, A., Leterrier, C., Guilloteau, L.A., Moisan, M.P., 2016. Effets durables d'un stress postnatal au cours de la vie du poulet d'élevage : recherche de marqueurs par analyse transcriptomique. Proceedings of the $34^{\text {éme }}$ Colloque de la Société de Neuroendocrinologie, 5-8 October 2016, Corte, France.

Gawienowski, A.M., Stacewicz-Sapuntzakis, M., 1978. Attraction of rats to sulfur compounds. Behav. Biol. 23, 267-270. 
Hogg, S., 1996. A review of the validity and variability of the elevated plus-maze as an animal model of anxiety. Pharmacol. Biochem. Behav. 54, 21-30.

Inagaki, H., Kiyokawa, Y., Takeuchi, Y., Mori, Y.,2012. Male rats respond to their own alarm pheromone. J. Vet. Med. Sci. 74, 79-82.

Inagaki, H., Kiyokawa, Y., Tamogami, S., Watanabe, H., Takeuchi, Y., Mori, Y., 2014. Identification of a pheromone that increases anxiety in rats. P. Natl. Acad. Sci. USA 111, 18751-18756. DOI: 10.1073/pnas. 1414710112

Jones, R.B., Gentle, M.J., 1985. Olfaction and behavioral modification in domestic chicks (Gallus domesticus). Physiol. Behav. 34, 917-924.

Jones, R.B., Roper, T.J., 1997. Olfaction in the domestic fowl: a critical review. Physiol. Behav. 62, 1009-1018.

Karlsson, A.-C., Jensen, P., Elgland, M., Laur, K., Fyrner, T., Konradsson, P., Laska, M., 2010. Red junglefowl have individual body odors. J. Exp. Biol. 213, 1619-1624. DOI: 10.1242/jeb.040279

Katz, R.J., Roth, K.A., Carroll, B.J., 1981. Acute and chronic stress effects on open field activity in the rat: Implications for a model of depression. Neurosci. Biobehav. Rev. 5, 247-251. DOI: 10.1016/0149-7634(81)90005-1

Kimball, B.A., Yamazaki, K., Kohler, D., Bowen, R.A., Muth, J.P., Opiekun, M., Beauchamp, G.K., 2013. Avian influenza infection alters fecal odor in mallards. PLoS ONE, 8(10), e75411. DOI: 10.1371/journal.pone.0075411

Koch, A., Leterrier, C., Collin, A., Mercerand, F., Rat, C., Delaveau, J., Grimaud, I., Constantin, P., Crochet, S., Cailleau-Audouin, E., Guilloteau, L.A., 2015. Effets durables d'une mise en élevage retardée des poussins sur leur santé et leurs performances. Proceedings of the $11^{\text {ème }}$ Journées de la Recherche Avicole et Palmidèdes à Foie Gras, 25-26 March 2015, Tours, France; pp. 966-970.

Krause, E.T., Schrader, L., Caspers, B.A., 2016. Olfaction in chicken (Gallus gallus): a neglected mode of social communication? Front. Ecol. Evol. 4, 94. DOI: 10.3389/fevo.2016.00094

Mackay-Sim, A., Laing, D., 1980. Discrimination of odors from stressed rats by non-stressed rats. Physiol. Behav. 24, 699-704.

Mackay-Sim, A., Laing, D., 1981. The sources of odors from stressed rats. Physiol. Behav. 27, 511513. DOI: 10.1016/0031-9384(81)90340-1

Mason, J.L., 1975. The influence of an olfactory stimulus on tonic immobility: evidence for an alarm pheromone in birds. M.Sc. Thesis, Tulane University, New Orleans, Louisiana, USA.

McCulloch, M., Jezierski, T., Broffman, M., Hubbard, A., Turner, K., Janecki, T., 2006. Diagnostic accuracy of canine scent detection in early- and late-stage lung and breast cancers. Integr. Cancer Ther. 5, 1-9. DOI: 10.1177/1534735405285096

Meese, G.B., Conner, D.J., Baldwin, B.A., 1975. Ability of the pig to distinguish between conspecific urine samples using olfaction. Physiol. Behav. 15, 121-125. 
Nelson, A.B., Alemadi, S.D., Wisenden, B.D., 2013. Learned recognition of novel predator odor by convict cichlid embryos. Behav. Ecol. Sociobiol. 67, 1269-1273. DOI: 10.1007/s00265-013-1554-1

Nevitt, G., Reid, K., Trathan, P., 2004. Testing olfactory foraging strategies in an Antarctic seabird assemblage. J. Exp. Biol. 207, 3537-3544. DOI:10.1242/jeb.01198

Nielsen, B.L., Jerôme, N., Saint-Albin, A., Ouali, C., Rochut, S., Zins, E.-L., Briant, C., Guettier, E., Reigner, F., Couty, I., Magistrini, M., Rampin, O., 2016. Oestrus odours from rats and mares: behavioural responses of sexually naive and experienced rats to natural odours and odorants. Appl. Anim. Behav. Sci. 176, 128-135. DOI: 10.1016/j.applanim.2016.01.014

Nielsen, B.L., Jerôme, N., Saint-Albin, A., Rampin, O., Maurin, Y., 2013. Behavioural response of sexually naïve and experienced male rats to the smell of 6-methyl-5-hepten-2-one and female rat faeces. Physiol. Behav. 120, 150-155. DOI: 10.1016/j.physbeh.2013.07.012

Nielsen, B.L., Jerôme, N., Saint-Albin, A., Thonat, C., Briant, C., Boué, F., Rampin, O., Maurin, Y., 2011. A mixture of odorant molecules potentially indicating oestrus in mammals elicits penile erections in male rats. Behav. Brain Res. 225, 584-589. DOI: 10.1016/j.bbr.2011.08.026

Nielsen, B.L., Rampin, O., Meunier, N., Bombail, V., 2015. Behavioral responses to odors from other species: introducing a complementary model of allelochemics involving vertebrates. Front. Neurosci. 9, 226. DOI: 10.3389/fnins.2015.00226

O’Mahony, S.M., Clarke, G., Borre, Y.E., Dinan, T.G., Cryan, J.F., 2015. Serotonin, tryptophan metabolism and the brain-gut-microbiome axis. Behav. Brain Res. 277, 32-48. DOI:

10.1016/j.bbr.2014.07.027

Pellow, S., Chopin, P., File, S.E., Briley, M., 1985. Validation of open:closed arm entries in an elevated plus-maze as a measure of anxiety in the rat. J. Neurosci. Meth. 14, 149-167.

Pitman, D.L., Ottenweller, J.E., Natelson, B.H., 1988. Plasma corticosterone levels during repeated presentation of two intensities of restraint stress: chronic stress and habituation. Physiol. Behav. 43, $47-55$.

Rampin, O., Jérôme, N., Briant, C., Boué, F., Maurin, Y., 2006. Are oestrus odours species specific? Behav. Brain Res. 172, 169-172. DOI: 10.1016/j.bbr.2006.04.005

Raynaud, A., Meunier, N., Acquistapace, A., Bombail, V., 2015. Chronic variable stress exposure in male Wistar rats affects the first step of olfactory detection. Behav. Brain Res. 291, 36-45. DOI: 10.1016/j.bbr.2015.05.013

Richards, K.M., Cotton, S.J., Sandeman, R.M., 2008. The use of detector dogs in the diagnosis of nematode infections in sheep feces. J. Vet. Behav. 3, 25-31.

Sakuma, K., Hayashi, S., Yasaka, Y., Nishijima, H., Funabashi, H., Hayashi, M., Matsuoka, H., Saito, M., 2013. Analysis of odor compounds in feces of mice that were exposed to various stresses during breeding. Exp. Anim. 62, 101-107.

Schaefer, M.L., Wongravee, K., Holmboe, M.E., Heinrich, N.M., Dixon, S.J., Zeskind, J.E., Kulaga, H.M., Brereton, R.G., Reed, R.R., Trevejo, J.M., 2010. Mouse urinary biomarkers provide 
signatures of maturation, diet, stress level, and diurnal rhythm. Chem. Sens. 35, 459-471. DOI: 10.1093/chemse/bjq032

Sherwin, C.M., Christiansen, S.B., Duncan, I.J.H., Erhard, H.W., Lay, D.C., Mench, J.A., O'Connor, C.E., Petherick, C.J., 2003. Guidelines for the ethical use of animals in applied animal behaviour research. Appl. Anim. Behav. Sci. 81, 291-305. DOI: 10.1016/S0168-1591(02)00288-5

Strauch, M., Lüdke, A., Münch, D., Laudes, T., Galizia, G., Martinelli, E., Lavra, L., Paolesse, R., Ulivieri, A., Catini, A., Capuano, R., Di Natale, C., 2014. More than apples and oranges - detecting cancer with a fruit fly's antenna. Sci. Rep. 4, 3576. DOI: 10.1038/srep03576

Tullo, E., Borgonovo, F., Fontana, I., Grilli, G., Guarino, M., Ferrante, V., 2017. Validation of an early warning system for enteric disorders in broiler farming. Proc. $8^{\text {th }}$ Euro. Conf. Precision Livest. Farming, 12-14 September 2017, Nantes, France, pp. 523-531.

Vaché, M., Ferron, J., Gouat, P., 2001. The ability of red squirrels (Tamiasciurus hudsonicus) to discriminate conspecific olfactory signatures. Rev. Can. Zoo. 79, 1296-1300. DOI: 10.1139/z01085

Valenta J.G., Rigby, M.K., 1968. Discrimination of the odor of stressed rats. Science, 161, 599-601. DOI: $10.1126 /$ science.161.3841.599

Walf, A.A., Frye, C.A., 2007. The use of the elevated plus maze as an assay of anxiety-related behavior in rodents. Nature Prot. 2, 322-328. DOI: 10.1038/nprot.2007.44

Weetjens, B.J., Mgode, G.F., Machang'u, R.S., Kazwala, R., Mfinanga, G., Lwilla, F., Cox, C., Jubitana, M., Kanyagha, H., Mtandu, R., Kahwa, A., Mwessongo, J., Makingi, G., Mfaume, S., Van Steenberge, J., Beyene, N.W., Billet, M., Verhagen, R., 2009. African pouched rats for the detection of pulmonary tuberculosis in sputum samples. Int. J. Tuberc. Lung Dis. 13, 737-743.

Willner, P., 2005. Chronic mild stress (CMS) revisited: consistency and behavioural-neurobiological concordance in the effects of CMS. Neuropsychobiol. 52, 90-110. DOI: 10.1159/000087097

Wyatt, T.D., 2010. Pheromones and signature mixtures: defining species-wide signals and variable cues for identity in both invertebrates and vertebrates. J. Comp. Physiol. A - Neuroethol. Sens. Neur. Behav. Physiol. 196, 685-700. DOI: 10.1007/s00359-010-0564-y

Yu, J.-B., Byun, H.-G., Myung-Suk So, M.-S., Huh, J.-S., 2005. Analysis of diabetic patient's breath with conducting polymer sensor array. Sensor. Actuator. B: Chem. 108, 305-308. DOI: 10.1016/j.snb.2005.01.040

Zalaquett,C., Thiessen, D., 1991.The effects of odors from stressed mice on conspecific behaviour. Physiol. Behav. 50, 221-227. DOI: 10.1016/0031-9384(91)90524-R 


\section{Figure headings}

Figure 1. a) Percentage of time spent in the open arms of the EPM during a 3-min test for each rat $(\mathrm{n}=12)$. Grey plus-sign and lines indicate the mean $(43 \%)$ and SD $(19.2 \%)$; b) Percentage of time $( \pm$ $\mathrm{SE}$ ) spent sniffing the faeces from stressed individuals relative to the time spent sniffing the control equivalents for each species. For comparison the relative time spent in the left hand side is shown for the tests with empty tea-balls. Each mean $(n=12)$ is compared to the $50 \%$ level indicated by the stippled line.
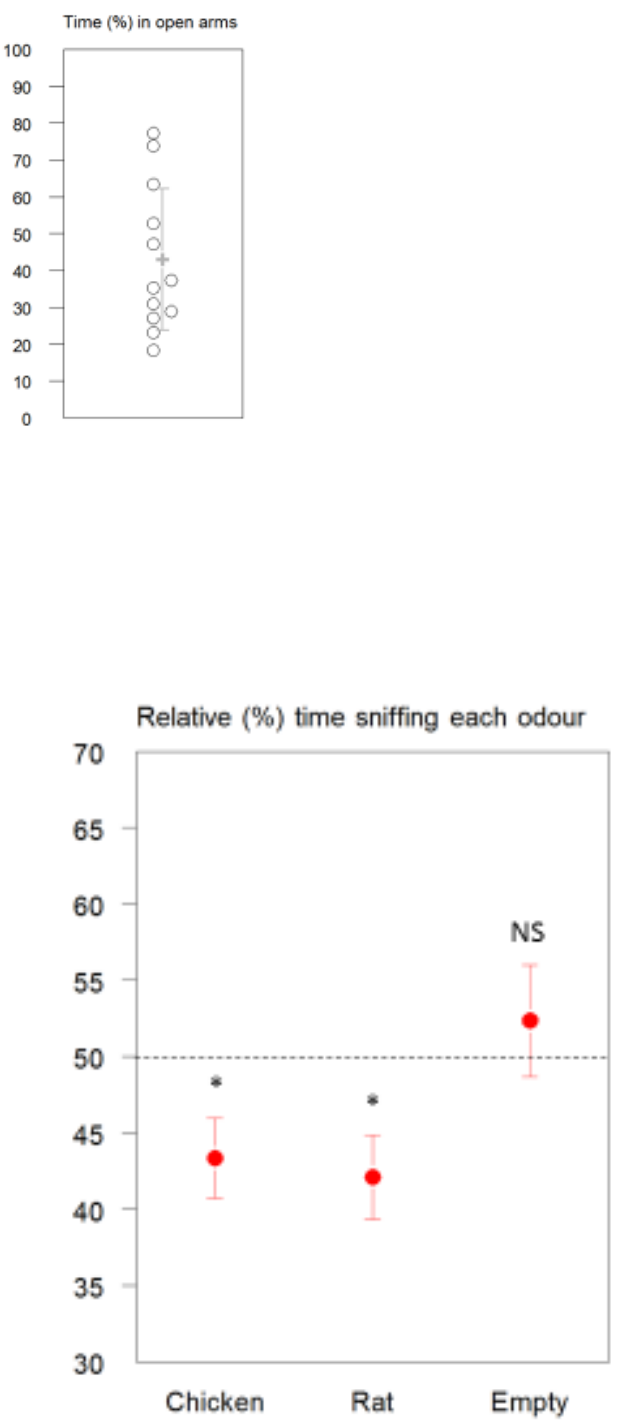
Figure 2. a) Number of lines crossed in a $5 \times 5$ grid during the initial 5 -min OF test for each rat $(n=16)$. Grey plus-sign and lines indicate the mean (93) and SD (21.1); b) Total duration of sniffing the odour source during the 10-min odour test for faeces from non-stressed (Stress -) and stressed (Stress +) rats (solid bars) and chickens (open bars), respectively; * $\mathrm{P}=0.044$.

Figure 2a

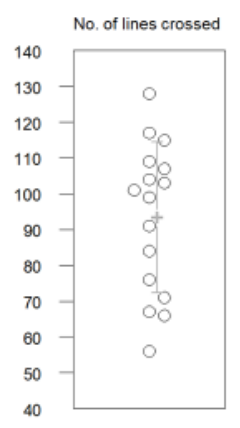

Figure 2b

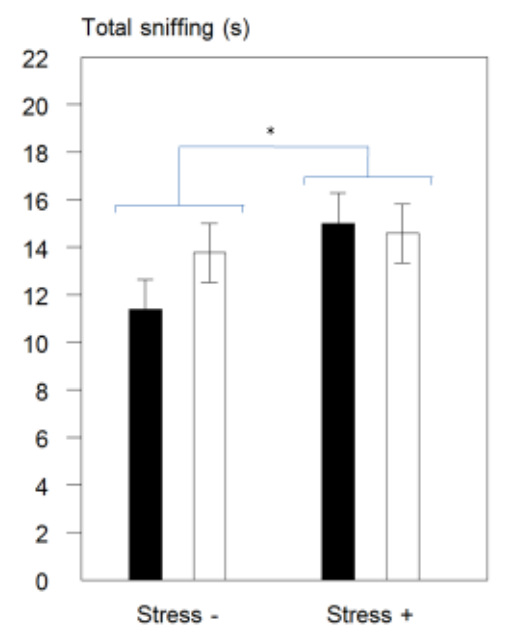


Figure 3. a) Total duration of freezing (s) and b) number of freezing episodes per test when rats were exposed to one of 7 odours for $10 \mathrm{~min}$. The asterisks indicate a significant difference from herb, the neutral control odour. Ratc: faeces from non-stressed rats; Rats: faeces from acutely stressed rats; and 4 types of chicken faeces: CC, CS, SC and SS, where the first letter refers to the stress treatment at hatching, and the second letter to the stress treatment at 13 days of age (C: Control, i.e. non-stressed; S: Stressed).
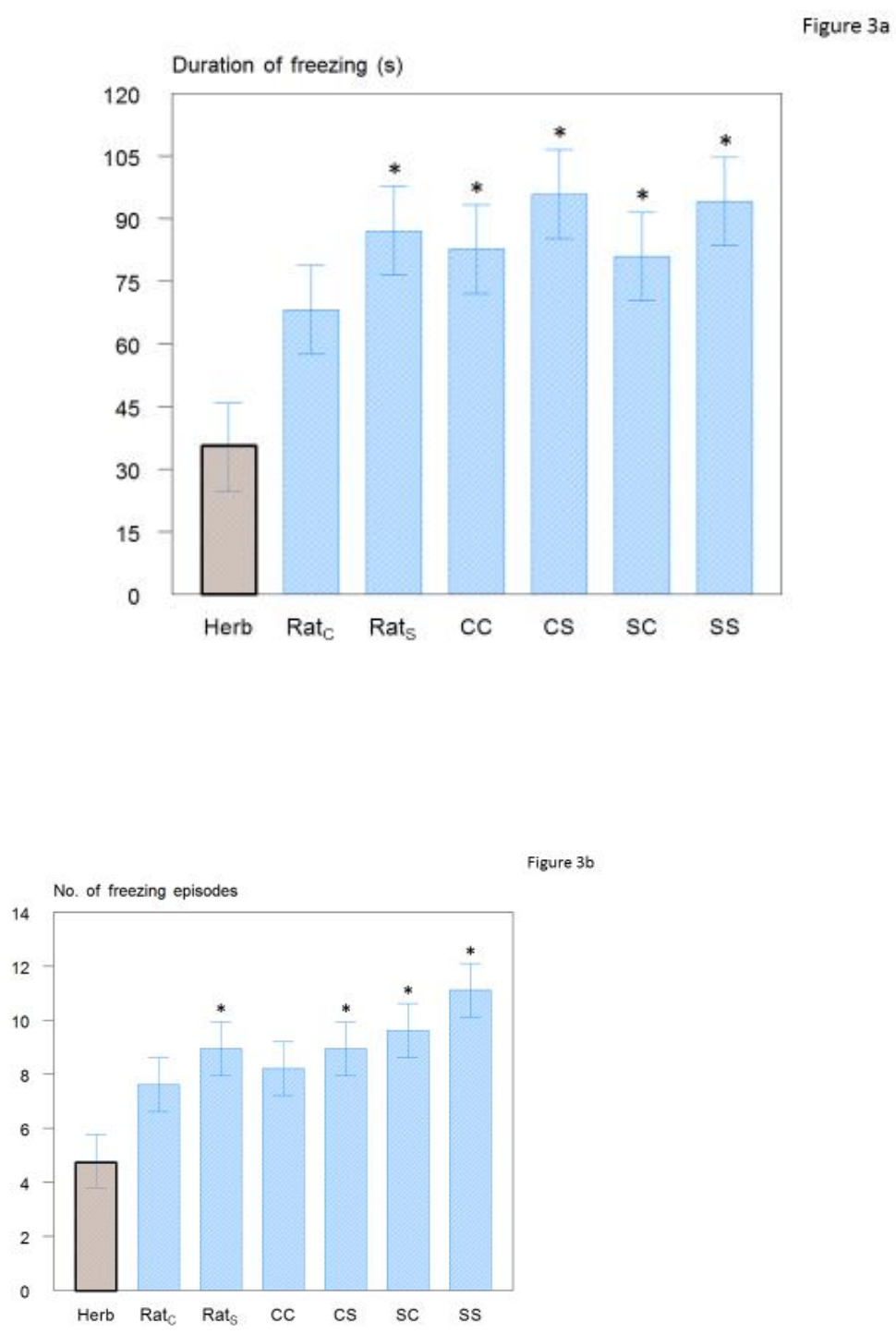
Figure 4. Percentage of rats displaying defensive burying for each of the odours tested; the corresponding number of rats are indicated on each bar (Friedman test; $\mathrm{s}=20.4 ; \mathrm{df}=6 ; \mathrm{P}=0.002$ ).

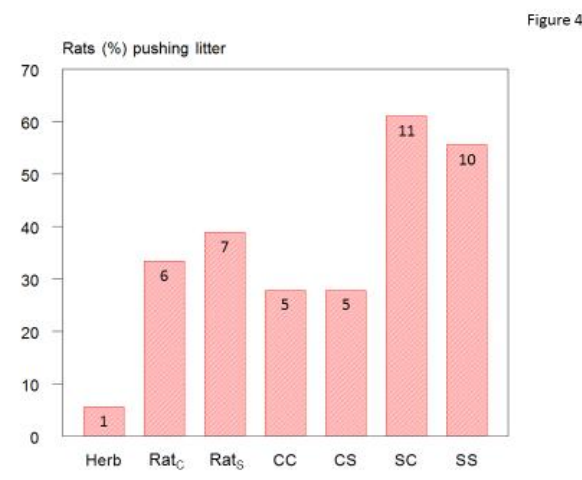


Figure 5. Bi-plots for the first two Principal Components (PC) obtained from the PLS-DA and scaled by the eigen-value for each PC; a) loadings for each of the 133 GC-MS peaks (plus signs) together with the scores for each faecal sample (diamonds; circled open symbols indicate samples from acutely stressed rats, $S_{\text {post }}$ ); b) same analysis, but using only the ten peaks not included in the stippled oval in a). The percentage of variance explained by each PC is indicated in brackets. See text for details.

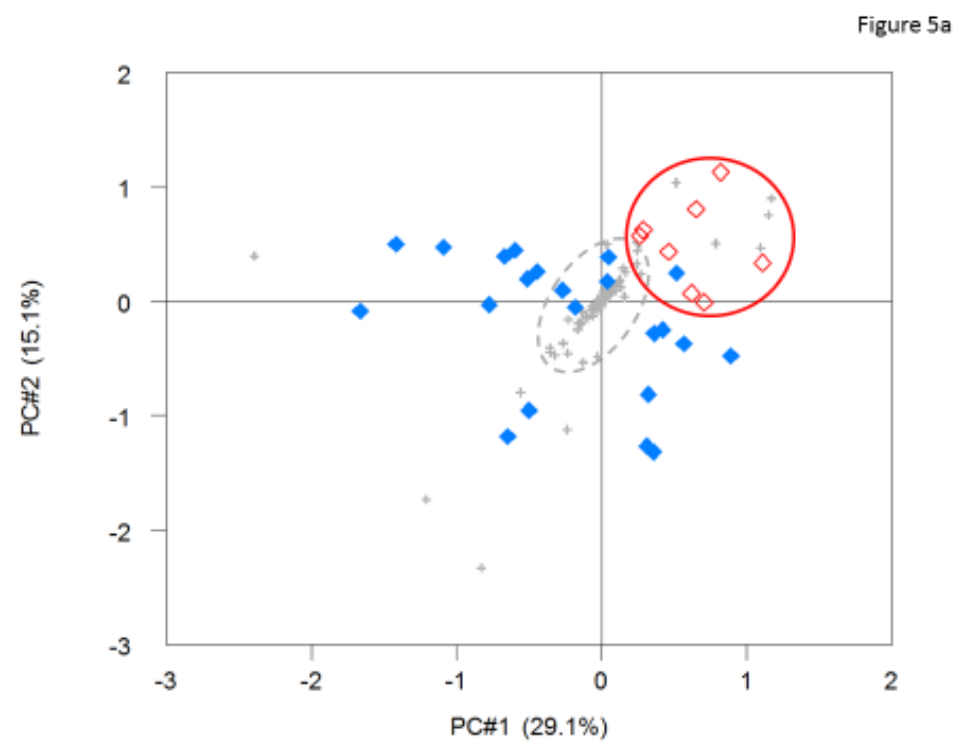


Figure 5b

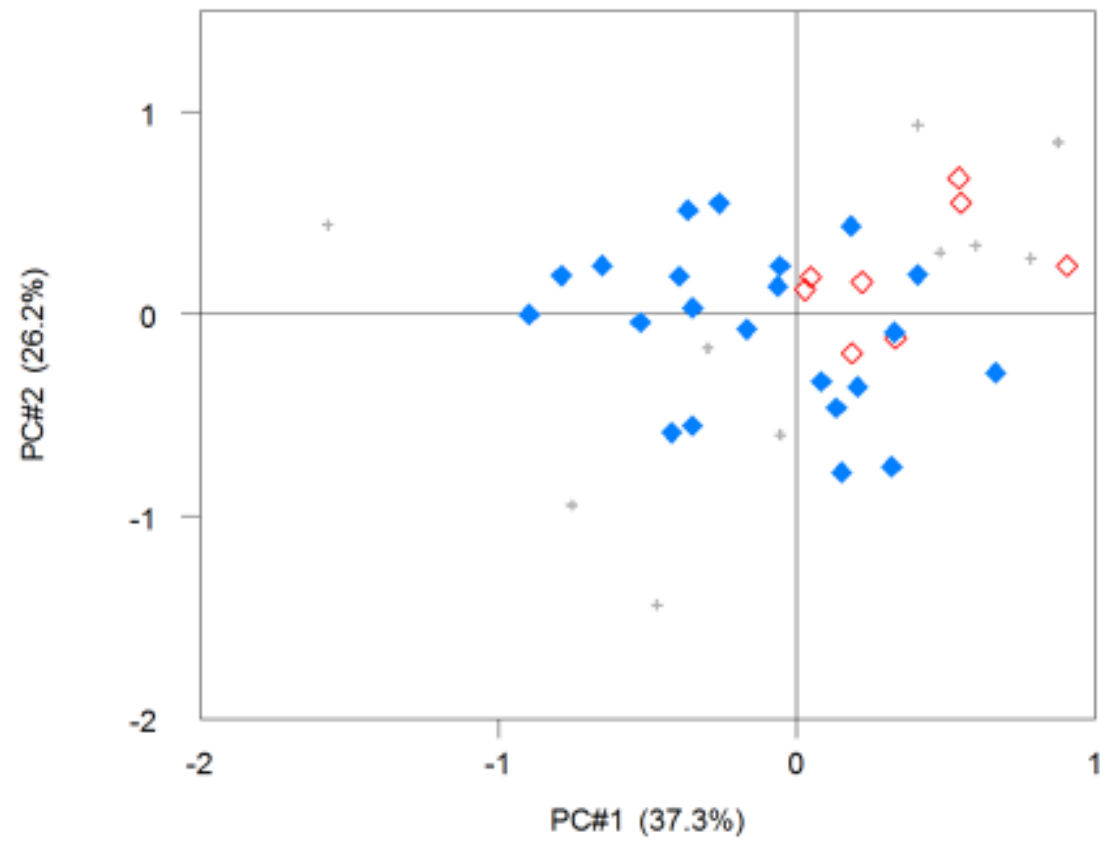

Comment citer ce document :

Bombail, V., Barret, B., Raynaud, A., Jerome, N., Saint Albin, A., Ridder, C., Collin, A.,

Leterrier, C., Guilloteau, L. A., Nielsen, B. L. (2018). In search of stress odours across species: behavioural responses of rats to faeces from chickens and rats subjected to various types of 
Figure 6. Weight $(\mathrm{g}, \pm \mathrm{SD})$ of faecal pellets in the four sample types (non-stressed (C) and acutely stressed (S) rats collected before (pre) and after (post) the treatment); a) acutely stressed rats ( $\mathrm{S}_{\text {post }}$; open diamonds) significantly increased their pellet weight following the stress treatment; b) same data as in a) but with lines linking samples from individual rats. The open diamond in $\mathrm{C}_{\text {post }}$ corresponds to the only non- $\mathrm{S}_{\text {post }}$ sample inside the solid circle in Figure $5 \mathrm{~b}$ (see text for details).

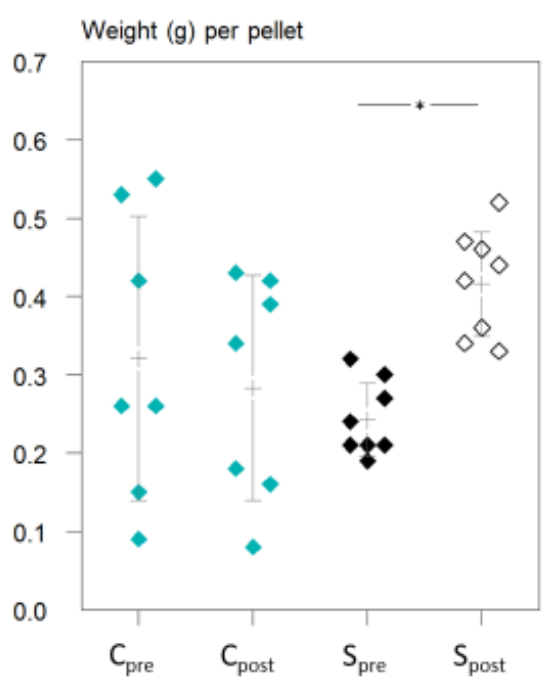

Figure 6a

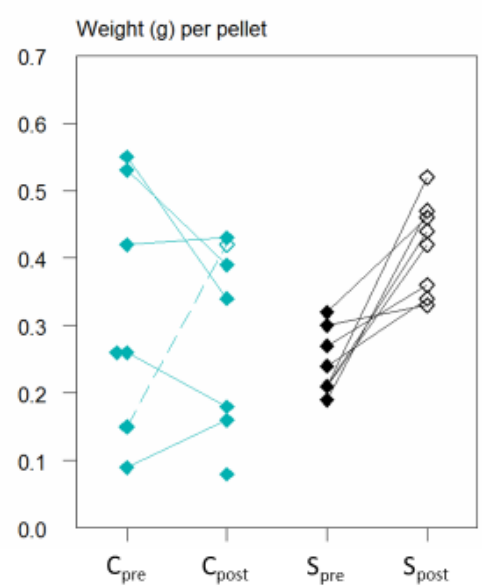

Figure 6b 
Table 1. Ten molecules identified as the most influential for the separation of stressed and non-stressed rat faeces by PLS-DA of all peaks identified by the GC-MS. Molecules in bold were found in the same quadrant as the stressed faecal samples in the PLS-DA shown in Figure 5a.

\begin{tabular}{|c|c|c|c|c|c|c|}
\hline \multicolumn{2}{|c|}{$\begin{array}{l}\text { Values from } \\
\text { Figure 5a }\end{array}$} & \multirow{2}{*}{$\begin{array}{l}\text { Found in n out } \\
\text { of } 30 \text { samples }\end{array}$} & \multirow[b]{2}{*}{ RT } & \multicolumn{3}{|r|}{ Chemical } \\
\hline PC\#1 & PC\#2 & & & structure & family & name \\
\hline 0.51 & 1.03 & 30 & 8.49 & C8H16 & alkene & 2-octene \\
\hline-2.39 & 0.39 & 30 & 30.98 & $\mathrm{C} 4 \mathrm{H} 8 \mathrm{O} 2$ & ketone & 3-hydroxy-2-butanone (acetoin) \\
\hline-0.24 & -1.12 & 14 & 35.98 & C2H6S3 & sulphide & dimethyl trisulphide (DMTS) \\
\hline-0.56 & -0.80 & 27 & 45.04 & $\mathrm{C} 10 \mathrm{H} 18 \mathrm{O}$ & alcohol & (possibly) 4-terpineol \\
\hline 1.10 & 0.47 & 30 & 45.81 & C4H8O2 & acid & butyric acid \\
\hline-1.21 & -1.73 & 28 & 48.75 & $\mathrm{C} 10 \mathrm{H} 18 \mathrm{O}$ & alcohol & (possibly) alpha-terpineol \\
\hline-0.83 & -2.33 & 30 & 54.13 & $\mathrm{C} 6 \mathrm{H} 12 \mathrm{O} 2$ & acid & hexanoic acid \\
\hline 1.17 & 0.90 & 30 & 62.87 & C7H8O & $\begin{array}{l}\text { phenol/ } \\
\text { alcohol }\end{array}$ & $\begin{array}{l}\text { phenol-2-methyl, phenol-3-methyl, } \\
\text { phenol-4-methyl or phenylmethanol }\end{array}$ \\
\hline 0.79 & 0.50 & 30 & 65.84 & C8H10O & phenol & $\begin{array}{l}\text { phenol-2-ethyl, phenol-3-ethyl, or } \\
\text { phenol-4-ethyl }\end{array}$ \\
\hline 1.15 & 0.75 & 30 & 75.19 & C8H7N & nitrogenous & indole \\
\hline
\end{tabular}

PLS-DA: Partial Least Squares Discriminant Analysis

GC-MS: gas chromatography coupled with mass spectrometry

PC: principal component

RT: retention time in the GC-MS 